\title{
Development of a Species-specific PCR Assay for Three Xanthomonas Species, Causing Bulb and Flower Diseases, Based on Their Genome Sequences
}

\author{
Chang-Gi Back ${ }^{1 \#}$, Seung-Yeol Lee ${ }^{1}$, Boo-Ja Lee ${ }^{2}$, Mi-Chi Yea ${ }^{1,2}$, Sang-Mok Kim ${ }^{2}$, In-Kyu Kang ${ }^{1}$, Jae-Soon Cha ${ }^{3}$ \\ and Hee-Young Jung ${ }^{1,4 *}$ \\ ${ }^{1}$ College of Agriculture and Life Sciences, Kyungpook National University, Daegu 702-701, Korea \\ ${ }^{2}$ Animal, Plant and Fisheries Quarantine and Inspection Agency, Anyang 430-016, Korea \\ ${ }^{3}$ Department of Plant Medicine, Chungbuk National University, Cheongju 361-763, Korea \\ ${ }^{4}$ Institute of Plant Medicine, Kyungpook National University, Daegu 702-701, Korea \\ ${ }^{\#}$ Current address: National Institute of Horticultural \& Herbal Science, Rural Development Administration, Wanju $565-$ \\ 852, Korea
}

(Received on April 4, 2015; Revised on June 12, 2015; Accepted on June 18, 2015)

In this study, we developed a species-specific PCR assay for rapid and accurate detection of three Xanthomonas species, $X$. axonopodis pv. poinsettiicola (XAP), X. hyacinthi $(\mathrm{XH})$ and $X$. campestris pv. zantedeschiae (XCZ), based on their draft genome sequences. XAP, XH and $\mathrm{XCZ}$ genomes consist of single chromosomes that contain 5,221, 4,395 and 7,986 protein coding genes, respectively. Species-specific primers were designed from variable regions of the draft genome sequence data and assessed by a PCR-based detection method. These primers were also tested for specificity against 17 allied Xanthomonas species as well as against the host DNA and the microbial community of the host surface. Three primer sets were found to be very specific and no amplification product was obtained with the host DNA and the microbial community of the host surface. In addition, a detection limit of $1 \mathrm{pg} / \mu \mathrm{l}$ per PCR reaction was detected when these primer sets were used to amplify corresponding bacterial DNAs. Therefore, these primer sets and the developed species-specific PCR assay represent a valuable, sensitive, and rapid diagnostic tool that can be used to detect three specific pathogens at early stages of infection and may help control diseases.

Keywords : bulb and flower disease, detection, draft genome sequence, species-specific primer, Xanthomonas spp.

Numerous species and pathovars of Xanthomonas cause

*Corresponding author.

Phone) +82-53-950-5760, FAX) +82-53-950-6758

E-mail) heeyoung@knu.ac.kr diseases in a variety of economically important plants. Symptoms of these diseases include cankers, spots, blights, and necrosis (Rockey, 2012). Three Xanthomonas species, $X$. axonopodis pv. poinsettiicola (XAP), X. hyacinthi $(\mathrm{XH})$ and $X$. campestris pv. zantedeschiae (XCZ), cause severe bulb and flower diseases in different ornamental plants and agriculturally important crops, like poinsettia, calla lily, hyacinth and some closely related bulb plants (Janse and Miller, 1983; Joubert and Truter, 1972; Lee et al., 2005b). Diseases caused by these pathogens are easily spread in the field by wind and rain. The unpredictable and severe nature of diseases caused by XAP, XH and XCZ to economically important plants makes them a constant threat. Thus, the development of a fast and specific method to ascertain whether symptoms are caused by these bacteria is the utmost importance to hyacinth and poinsettia plant growers (Van Doorn, 2001). Furthermore, bulb and flower production is no longer limited to specific countries; its production and transportation have significantly increased in Asia during the last decade. Therefore, researchers provided diagnostic tools to prevent infection (Benschop, 2010). The previous bacterial detection certified techniques relied mainly upon plant bioassays and culture based approaches (Smith et al., 1997). These methods are expensive for routine usage, often exceedingly time-consuming, and only allow for a presumptive identification, but does not discriminate pathogens at the species or pathovar level (Lopez et al., 2003). To overcome these limitations, more accurate and efficient molecular-based detection methods have been proposed as alternatives. Particularly, DNA based techniques, which have already been validated, showed their potential in routine surveys (Lopez et al., 2009).

The genome sequence of a pathogen is an important 
source to study the pathogenesis mechanism and develop specific detection methods for pathogen in particular having narrow host range (Lee et al., 2005a). Furthermore, the genome sequencing of $X$. citri pv. malvacearum has enabled researchers to develop a specific PCR assay for the detection of pathogens from plant materials based on draft genome sequences (Showmaker et al., 2014). Furthermore, DNA assays used for the detection of these pathogens are mainly based on $16 \mathrm{~S}$ ribosomal DNA amplification and analysis of DNA restriction fragment length polymorphism, which does not allow the discrimination of these pathogens at the species level (Van Doorn, 2001).

The present study was designed to analyze the genome of XAP, XH and XCZ and develop a rapid, sensitive, and species-specific PCR assay for their detection based on their genomic analysis. Various primer sets were designed using bioinformatics methods based on the draft genome sequence of XAP, XH and XCZ. The sensitivity and specificity of the primers to these species in comparison with other Xanthomonas species as well as the host DNA and the microbial community of the host surface were also tested.

\section{Materials and Methods}

Bacterial strains and DNA extraction. In this study, three Xanthomonas species, XAP (NCPPB 581), XH (NCPPB 205) and XCZ (NCPPB 4326) were obtained from the National Collection of Plant Pathogenic Bacteria (NCPPB). All Xanthomonas species were cultured on LB agar (Difco, Detroit, MI, USA) and incubated at $28^{\circ} \mathrm{C}$ for $48 \mathrm{~h}$. Yellow colonies of Xanthomonas were subcultured until pure colonies were obtained. Genomic DNA was extracted from bacterial cells using HiGene Genomic DNA Prep Kit (BIOFACT, Daejeon, Korea) according to the manufacturer's instructions. The extracted DNA was confirmed by agarose gel (1\%) electrophoresis and genomic DNA was then quantified by using PicoDrop ${ }^{\mathrm{TM}}$ Pico100 (PicoDrop Technologies, Cambridge, UK).

Genome sequencing and annotation. XAP, XH and XCZ genome sequences were determined on the Ion Torrent personal genome machine (Life Technologies, Korea). Libraries were produced using $1 \mu \mathrm{g}$ of total genomic DNA and an Ion Xpress Plus fragment library kit comprising of the Ion Shear chemistry. During the emulsion PCR, each diluted library was used as the template for clonal amplification on Ion Sphere particles and the enriched amplification products were then loaded onto an Ion 316 chip and sequenced using 500 sequencing cycles. Five hundred sequencing cycles result in an average reading length of approximately 200 nucleotides. The MIRA program (version 4.0.2.1) was then used for de novo assembly. The genome projects for XAP, XH and XCZ are listed in the Genome OnLine Database (GOLD) as projects Gi0074998, Gi0075001 and Gi0074999, respectively. The JGI microbial genome automated annotation pipeline (Mavromatis et al., 2009) was used for the annotation of the selected genome followed by manual curation using the GenePRIMP software program. The predicted coding sequences (CDSs) were then translated and used to search the NCBI non redundant database and the TIGRFam, Uni-Prot, PRIAM, Pfam, COG, KEGG and InterPro databases. Additional functional annotations and gene predictions were performed by using the IMGER platform.

Primer design. The bioinformatics approach was used to select target DNA sequences for Xanthomonas speciesspecific primer designing from the draft genome sequence DNA sequences were selected randomly and a standard nucleotide BLAST search was performed on the NCBI database (http://www.ncbi.nlm.nih.gov). Through BLAST analysis, unique regions in XAP, XH and XCZ genome were chosen to obtain specific target sequences for primer design. The ClustalW software (http://clustalw.ddbj.nig. ac.jp/top-e.html) was used to design specific primers from the obtained consensus sequences, following multiple alignments of several Xanthomonas sequences.

Primer specificity. A total of 36 primer sets (12 primer sets for each species) were tested for species specificity against XAP, XH and XCZ (data not shown). Among them, three primer pairs, XPN: XPN-F (5'-TGT TGG TGT CGA CGT ACA GC-3')/XPN-R (5'-TGA CAC ACG CAG CGT AGG AG-3'), XHG:XHG-F (5'-ACC ACC ACG TCG CTG GGT TCC-3')/XHG-R (5'-CGG CGC GCT GGC GAC CCA CCG-3') and XZRN: XZRN-F(5'TTC TTC TCC GTC CTC CCT CA-3')/XZRN-R (5'-ACA GGT GCC CAC CGG TTA CT-3') were then selected on the basis of their amplification results and specificity to respective strains. The specificity of these primers was assessed on genomic DNA extracted from pure bacterial cultures: 9 strains of XAP (NCPPB 581, 1939 and 3948), XH (NCPPB 205, 1622 and MAFF 301390), XCZ (NCPPB 4326, 2978 and MAFF 301641) from different origins, and 17 strains of allied Xanthomonas species (Table 1). Furthermore, these primers were also tested for specificity against the host DNA and the microbial community of the host surface. PCR amplification was performed in a total volume of $20 \mu \mathrm{l}$ containing $1 \times$ reaction buffer, $0.4 \mu \mathrm{dNTP}$ 
Table 1. Summary of Xanthomonas axonopodis pv. poinsettiicola (XAP), Xanthomonas hyacinthi (XH) and Xanthomonas campestris pv. zantedeschiae (XCZ) strains and allied bacterial strains

\begin{tabular}{|c|c|c|c|}
\hline No & Bacterium & Condition & Provided by \\
\hline 1 & Xanthomonas axonopodis pv. poinsettiicola & Cultures & $\operatorname{NCPPB}^{1}(581)$ \\
\hline 2 & $X$. axonopodis pv. poinsettiicola & Cultures & $\operatorname{NCPPB}^{1}(1939)$ \\
\hline 3 & X. axonopodis pv. poinsettiicola & Cultures & $\mathrm{NCPPB}^{1}(3948)$ \\
\hline 4 & X. hyacinthi & Cultures & $\mathrm{NCPPB}^{1}(205)$ \\
\hline 5 & X. hyacinthi & Cultures & $\operatorname{NCPPB}^{1}(1622)$ \\
\hline 6 & X. hyacinthi & Cultures & $\operatorname{MAFF}^{2}(301390)$ \\
\hline 7 & X. campestris pv. zantedeschiae & Cultures & $\operatorname{NCPPB}^{1}(4326)$ \\
\hline 8 & X. campestris pv. zantedeschiae & Cultures & $\operatorname{NCPPB}^{1}(2978)$ \\
\hline 9 & $X$. campestris pv. zantedeschiae & Cultures & $\operatorname{MAFF}^{2}(301641)$ \\
\hline 10 & X. campestris pv. campestris & DNA & Chungbuk National University $^{3}$ \\
\hline 11 & $X$. citri pv. glycines & DNA & Chungbuk National University $^{3}$ \\
\hline 12 & $X$. arboricola $\mathrm{pv}$. fragariae & DNA & Chungbuk National University ${ }^{3}$ \\
\hline 13 & $X$. arboricola pv. juglandis & DNA & Chungbuk National University ${ }^{3}$ \\
\hline 14 & X. translucens & DNA & Chungbuk National University ${ }^{3}$ \\
\hline 15 & $X$. arboricola pv. populi & DNA & Chungbuk National University $^{3}$ \\
\hline 16 & $X$. axonopodis pv. allii & DNA & Animal and Plant Quarantine Agency \\
\hline 17 & $X$. axonopodis pv. citri & DNA & Animal and Plant Quarantine Agency \\
\hline 18 & X. axonopodis pv. phaseoli & DNA & Animal and Plant Quarantine Agency \\
\hline 19 & X. campestris pv. armoraciae & DNA & Animal and Plant Quarantine Agency \\
\hline 20 & X. campestris pv. diffenbachiae & DNA & Animal and Plant Quarantine Agency \\
\hline 21 & $X$. campestris pv. glycines & DNA & Animal and Plant Quarantine Agency \\
\hline 22 & X. campestris pv. malvacearum & DNA & Animal and Plant Quarantine Agency \\
\hline 23 & X. campestris pv. poinsettiicola & DNA & Animal and Plant Quarantine Agency \\
\hline 24 & X. campestris pv. vesicatoria & DNA & Animal and Plant Quarantine Agency \\
\hline 25 & X. cucurbitae & DNA & Animal and Plant Quarantine Agency \\
\hline 26 & X. oryzae pv. oryzae & DNA & Animal and Plant Quarantine Agency \\
\hline
\end{tabular}

${ }^{1} \mathrm{NCPPB}$, National Collection of Plant Pathogenic Bacteria; ${ }^{2} \mathrm{MAFF}$, Ministry of Agriculture, Forestry and Fisheries; ${ }^{3}$ These DNA samples were provided by Professor Jae-Soon Cha, Chungbuk National University, Cheongju, South Korea.

(10 mM), 0.1 $\mu \mathrm{l} \mathrm{Taq} \mathrm{(SolgTM} \mathrm{h-Taq} \mathrm{DNA} \mathrm{Polymerase),}$ $1 \mu \mathrm{l}(10 \mathrm{pm} / \mu \mathrm{l})$ primers, and $1 \mu \mathrm{l}(10 \mathrm{ng} / \mu \mathrm{l})$ of DNA. The PCR program for XHG and XPN primer sets consisted of an initial denaturation at $95^{\circ} \mathrm{C}$ for $5 \mathrm{~min}$ followed by $35 \mathrm{cy}$ cles at $95^{\circ} \mathrm{C}$ for $30 \mathrm{~s}, 65^{\circ} \mathrm{C}$ for $20 \mathrm{~s}$ and $72^{\circ} \mathrm{C}$ for $30 \mathrm{~s}$ with a final extension step at $72^{\circ} \mathrm{C}$ for $5 \mathrm{~min}$. For the primer set $\mathrm{XZRN}$, the amplification conditions were as follows: initial denaturation at $95^{\circ} \mathrm{C}$ for 5 min followed by 35 cycles at $95^{\circ} \mathrm{C}$ for $30 \mathrm{~s}, 60^{\circ} \mathrm{C}$ for $20 \mathrm{~s}$ and $72^{\circ} \mathrm{C}$ for $30 \mathrm{~s}$ with a final extension step at $72^{\circ} \mathrm{C}$ for $5 \mathrm{~min}$. The amplified PCR products were separated by gel electrophoresis using $1.5 \%$ agarose. The gel was stained with ethidium bromide and visualized with a UV transilluminator.

Primer sensitivity and PCR efficiency. Three primer sets XPN, XHG and XZRN were selected based on their high specificity to XAP, XH and XCZ, respectively. To check their sensitivity, a test was performed using a 10 fold dilutions of purified genomic DNA from XAP, XH and XCZ strains. The concentration of the samples used to test the specificity of the primers was $10 \mathrm{ng} / \mu \mathrm{l}$. The XAP, XH and $\mathrm{XCZ}$ genomic DNA was then diluted to $10^{0}, 10^{-1}, 10^{-2}$, $10^{-3}$, and $10^{-4} \mathrm{ng} / \mu \mathrm{l}$ with DDW to test primer sensitivity. Furthermore, to check the efficiency of the primers to amplify XAP, XH and XCZ from four symptomless plants (E. pulcherrima, H. orientalis, $M$. armeniacum, and $Z$. aethiopica), plant tissues $(0.2 \mathrm{~g})$ from four host plants, and their respective pathogenic bacterial cells $\left(1 \times 10^{9} \mathrm{cfu} / \mu \mathrm{l}\right)$ were mixed and subjected to grinding. Genomic DNA was extracted from these mixtures by using HiGene Genomic DNA Prep Kit (BIOFACT) following the manufacturer's instruction. The PCR efficiency of the three primer sets, 
XHG, XPN and XZRN, was checked on these DNA mixtures.

\section{Results and Discussion}

Genome properties. The properties and statistical analyses for the genome of the three Xanthomonas species, XAP, $\mathrm{XH}$ and $\mathrm{XCZ}$, are summarized in Table 2. The genes distribution into $\mathrm{COG}$ functional categories for each genome is detailed in Table 3 and Fig. 1. The genome of XAP, XH and $\mathrm{XCZ}$ consists of single chromosomes and contains $5,221,4,395$ and 7,986 protein coding genes, respectively. Moreover, a total of 3,868, 3,318 and 4,754 protein coding genes were assigned a putative function (Table 2). These species showed genomic similarities with previously reported Xanthomonas species, $X$. oryzae pv. oryzae, $X$. campestris pv. vesicatoria and $X$. fuscans subsp. fuscans (Darrasse et al., 2013; Ochiai et al., 2005; Thieme et al., 2005). Similarly, high $\mathrm{G}+\mathrm{C}$ contents were found in XAP, $\mathrm{XH}$ and $\mathrm{XCZ}$, which is a common characteristic of most genera within the Xanthomonadaceae family (Darrasse et al., 2013). Furthermore, XAP, XH and XCZ genomic information facilitated the selection of species-specific primers based on variable regions in their genome. In addition, previous reports showed that, for the prevention of bacterial disease dissemination, early detection of Xanthomonas species is the most effective measure and conventional protocols carried out by the phytosanitary authorities are laborious, costly and excessively time consuming, which are major drawbacks for extensive surveillance of these pathogens (Lopez et al., 2003). However, over the last two decades, many DNA-based approaches, mostly PCR-based techniques, have been used for the detection of various pathogenic bacteria in general and Xanthomonas species in particular (Palacio-Bielsa, 2009). These PCR assays have been implemented successfully for the detection and identification of economically important Xanthomonas species such as $X$. axonopodis pv. dieffenbachiae, $X$. axonopodis pv. citri, $X$. citri subsp. citri, X. campestris pv. citri and $X$. fragariae (Adikini et al., 2011). Furthermore, previous studies also reported that Xanthomonas pathovars are difficult to differentiate as they are almost indistinguishable in bacteriological and biochemical traits (Bradbury, 1984).

Primer specificity for the detection of XAP, XH and XCZ. All 36 primer sets (12 for each strain) tested amplified against their respective strains (data not shown). The primer sets, XPN, XHG and XZRN, were then selected based on their best amplification results and specificity to their respective strains. The expected band of $966 \mathrm{bp}, 1,049$ bp and 328 bp for the three primer sets XHG, XPN and XZRN, respectively, were obtained (Fig. 1). These primer sets also allowed the amplification of 9 strains of XAP, XH and XCZ (data not shown). However, the evaluation results against 17 allied Xanthomonas species showed negative amplification with all tested strains. Consistent positive amplification was only achieved in their respective strains (XAP, XH and XCZ) (data not shown). Moreover, no amplification was observed when assessing these primer pairs against their respective host DNAs and microbial community of the host surface (Fig. 2).

Table 2. General features of three Xanthomonas species, X. axonopodis pv. poinsettiicola (XAP), X. hyacinthi (XH) and X. campestris pv. zantedeschiae (XCZ)

\begin{tabular}{lccc}
\hline Attribute & XAP & XH & XCZ \\
\hline Genome size (bp) & $5,094,606$ & $4,290,973$ & $5,64,3059$ \\
DNA coding region (bp) & $4,289,430$ & $3,635,686$ & $4,478,823$ \\
DNA G + C number of bases & $64.77 \%$ & $67.42 \%$ & $64.52 \%$ \\
Total number of genes & 5,287 & 4,459 & 8,090 \\
Protein coding genes & 5,221 & 4,395 & 7,986 \\
RNA genes & 66 & 64 & 104 \\
rRNA genes & 4 & 3 & 11 \\
tRNA genes & 53 & 51 & 73 \\
Protein coding genes with predicted function & 3,868 & 3,318 & 4,754 \\
CDS assigned to COGs & 2,812 & 1,547 \\
CDS assigned to KOGs & be & 593 & 333 \\
CDS with signal peptides & 652 & 452 & 502 \\
Genes coding for transmembrane proteins & 585 & 908 & 1,344 \\
\hline
\end{tabular}

a) CDS; coding sequences, COG; clusters of orthologous group

b) KOG; eukaryotic orthologous group 
Table 3. Number of genes associated with 25 general COG functional categories

\begin{tabular}{|c|c|c|c|c|c|c|c|}
\hline \multirow{2}{*}{ Code } & \multicolumn{2}{|c|}{ XAP } & \multicolumn{2}{|r|}{$\mathrm{XH}$} & \multicolumn{2}{|r|}{$\mathrm{XCZ}$} & \multirow{2}{*}{ Description } \\
\hline & Value & $\%$ of total ${ }^{\mathrm{a}}$ & Value & $\%$ of total ${ }^{\mathrm{a}}$ & Value & $\%$ of total ${ }^{\mathrm{a}}$ & \\
\hline $\mathrm{E}$ & 178 & 6.6 & 176 & 7.3 & 99 & 5.72 & Amino acid transport and metabolism \\
\hline G & 162 & 6.01 & 127 & 5.27 & 86 & 4.97 & Carbohydrate transport and metabolism \\
\hline $\mathrm{D}$ & 24 & 0.89 & 23 & 0.95 & 19 & 1.1 & Cell cycle control, cell division, and chromosome partitioning \\
\hline $\mathrm{N}$ & 92 & 3.41 & 91 & 3.77 & 60 & 3.47 & Cell motility \\
\hline M & 161 & 5.97 & 131 & 5.43 & 97 & 5.61 & Cell wall, membrane, and envelope biogenesis \\
\hline $\mathrm{B}$ & 1 & 0.04 & 0 & 0 & 1 & 0.06 & Chromatin structure and dynamics \\
\hline $\mathrm{H}$ & 110 & 4.08 & 85 & 3.52 & 54 & 3.12 & Coenzyme transport and metabolism \\
\hline $\mathrm{Z}$ & 1 & 0.04 & 2 & 0.08 & 1 & 0.06 & Cytoskeleton \\
\hline $\mathrm{V}$ & 39 & 1.45 & 49 & 2.03 & 19 & 1.1 & Defense mechanisms \\
\hline $\mathrm{C}$ & 147 & 5.45 & 150 & 6.22 & 105 & 6.07 & Energy production and conversion \\
\hline $\mathrm{S}$ & 265 & 9.83 & 216 & 8.96 & 186 & 10.75 & Function unknown \\
\hline $\mathrm{R}$ & 308 & 11.42 & 253 & 10.49 & 206 & 11.91 & General function prediction only \\
\hline $\mathrm{P}$ & 135 & 5.01 & 139 & 5.76 & 86 & 4.97 & Inorganic ion transport and metabolism \\
\hline $\mathrm{U}$ & 118 & 4.38 & 111 & 4.6 & 63 & 3.64 & Intracellular trafficking, secretion, and vesicular transport \\
\hline I & 110 & 4.08 & 98 & 4.06 & 68 & 3.93 & Lipid transport and metabolism \\
\hline $\mathrm{F}$ & 54 & 2 & 52 & 2.16 & 36 & 2.08 & Nucleotide transport and metabolism \\
\hline $\mathrm{O}$ & 114 & 4.23 & 96 & 3.98 & 74 & 4.28 & Posttranslational modification, protein turnover, chaperones \\
\hline $\mathrm{L}$ & 109 & 4.04 & 99 & 4.1 & 55 & 3.18 & Replication, recombination, and repair \\
\hline A & 1 & 0.04 & 1 & 0.04 & 1 & 0.06 & RNA processing and modification \\
\hline Q & 60 & 2.23 & 68 & 2.82 & 30 & 1.73 & Secondary metabolites biosynthesis, transport, and catabolism \\
\hline $\mathrm{T}$ & 175 & 6.49 & 117 & 4.85 & 128 & 7.4 & Signal transduction mechanisms \\
\hline $\mathrm{K}$ & 185 & 6.86 & 185 & 7.67 & 147 & 8.5 & Transcription \\
\hline $\mathrm{J}$ & 147 & 5.45 & 143 & 5.93 & 109 & 6.3 & Translation, ribosomal structure, and biogenesis \\
\hline $\mathrm{W}$ & 0 & 0 & 0 & 0 & 0 & 0 & Extracellular structures \\
\hline \multirow[t]{2}{*}{$\mathrm{Y}$} & 0 & 0 & 0 & 0 & 0 & 0 & Nuclear structure \\
\hline & 2875 & 54.38 & 2312 & 51.85 & 6543 & 80.88 & Not in COGs \\
\hline
\end{tabular}

${ }^{\text {a) }}$ The total is based on the total number of genes associated with COG categories.

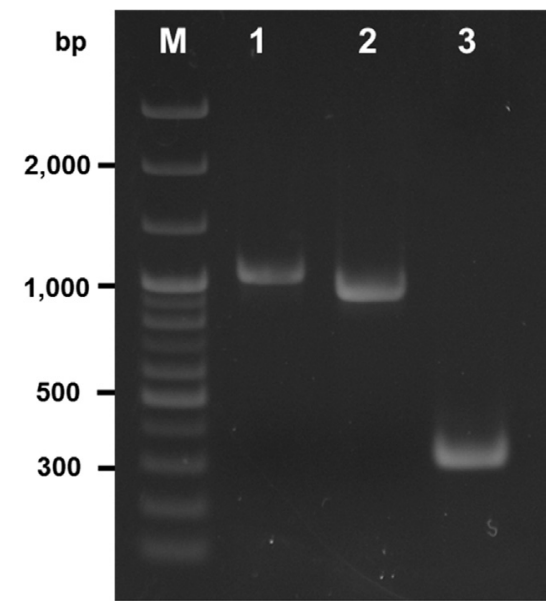

Fig. 1. Expected positive amplification for the three primer pairs XPN, XHG and XZRN against three Xanthomonas species, $\mathrm{XAP}, \mathrm{XH}$ and $\mathrm{XCZ}$, respectively. Lane M, 100 bp ladder; lane 1, $\mathrm{XPN}$ primer set against XAP, lane 2, XHG primer set against XH and lane 3, XZRN primer set against XCZ.
According to these results, these primers are specific to $\mathrm{XAP}, \mathrm{XH}$ and XCZ. Thus, they can be used for the detection and routine diagnosis of these Xanthomonas strains in the field. To date, there is no report of species-specific primers for the detection of these species, although, many techniques, including DNA assays, are available for the detection of Xanthomonas species, which are mainly based on 16S ribosomal DNA amplification (Louws et al., 1994). However, these methods are not suitable for specific detection at the species and pathovar level. Therefore, in this study, we successfully developed species-specific primer pairs, which showed high specificity for the detection of these pathogens. The specificity of these primers relies upon the unique features of the template sequences that were used for primer designing. The XPN, XHG and XZRN primers were randomly designed from draft genome sequences. The portions of the sequence unique to $\mathrm{XAP}, \mathrm{XH}$ and XCZ were identified by multiple sequence alignment and then used for these species-specific primer 


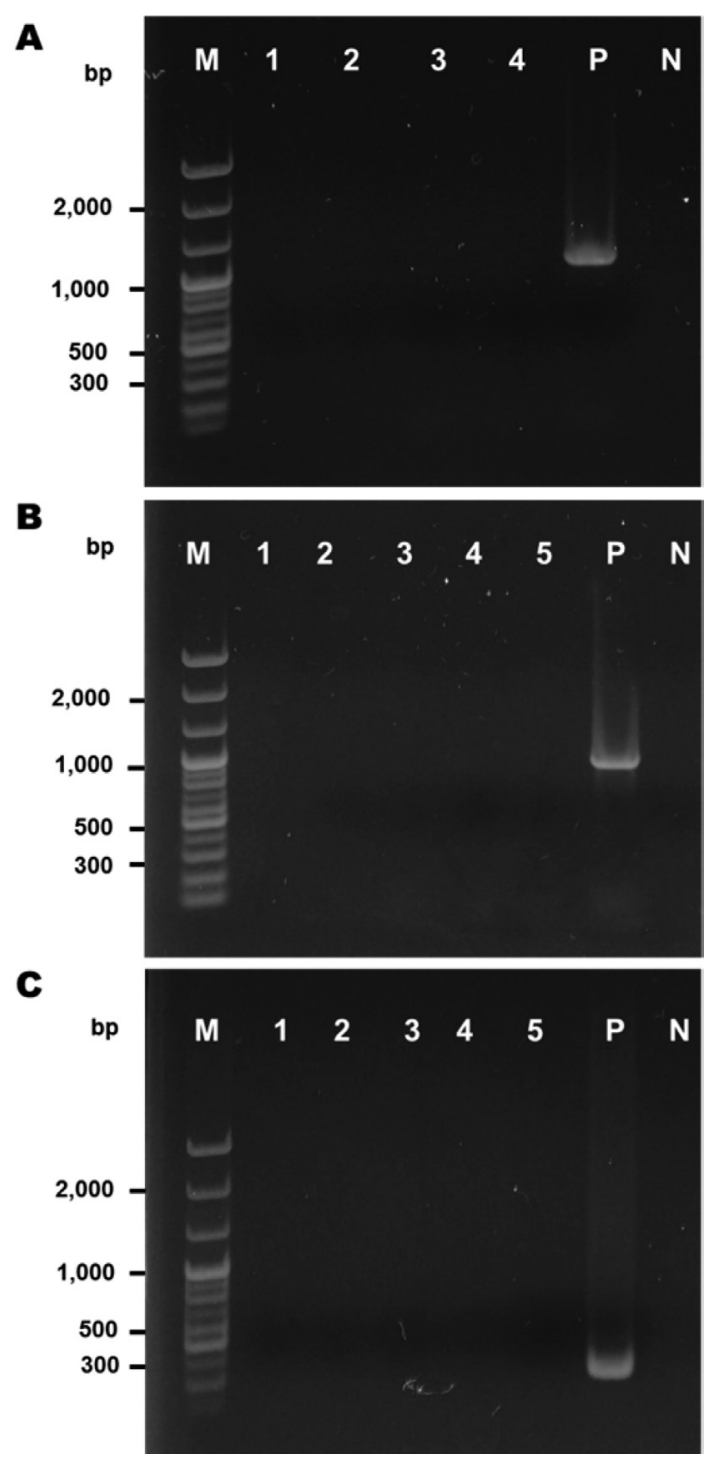

Fig. 2. Specificity of the selected primers (A) XPN against XAP host (Euphorbia pulcherrima), (B) XHG against XH host (Hyacinthus orientalis) and (C) XZRN against XCZ host (Zantedeschia aethiopica) DNA and microbial community of the respective host surface. (A) Lane M, 100 bp ladder; lane 1, host root; lane 2, host leaves; lane 3, root surface microbial community; lane 4, leaves surface microbial community; lane P, XAP and lane N, negative control. (B) and (C) Lane M, 100 bp ladder; lane 1, host root; lane 2, host leaves; lane 3, host bulb; lane 4, root surface microbial community; lane 5, bulb surface microbial community; lane P, $\mathrm{XH}$ and $\mathrm{XCZ}$ and lane $\mathrm{N}$, negative control.

designing. The respective genes are nucleoside hydrolase for primer XPN, glucosylphosphate transferase for XHG and resistance-Nodulation-Cell Division (RND) for XZRN. The lack of amplification in all allied Xanthomonas spp. demonstrates a high degree of specificity for these primers and their ability to consistently detect their respective species.

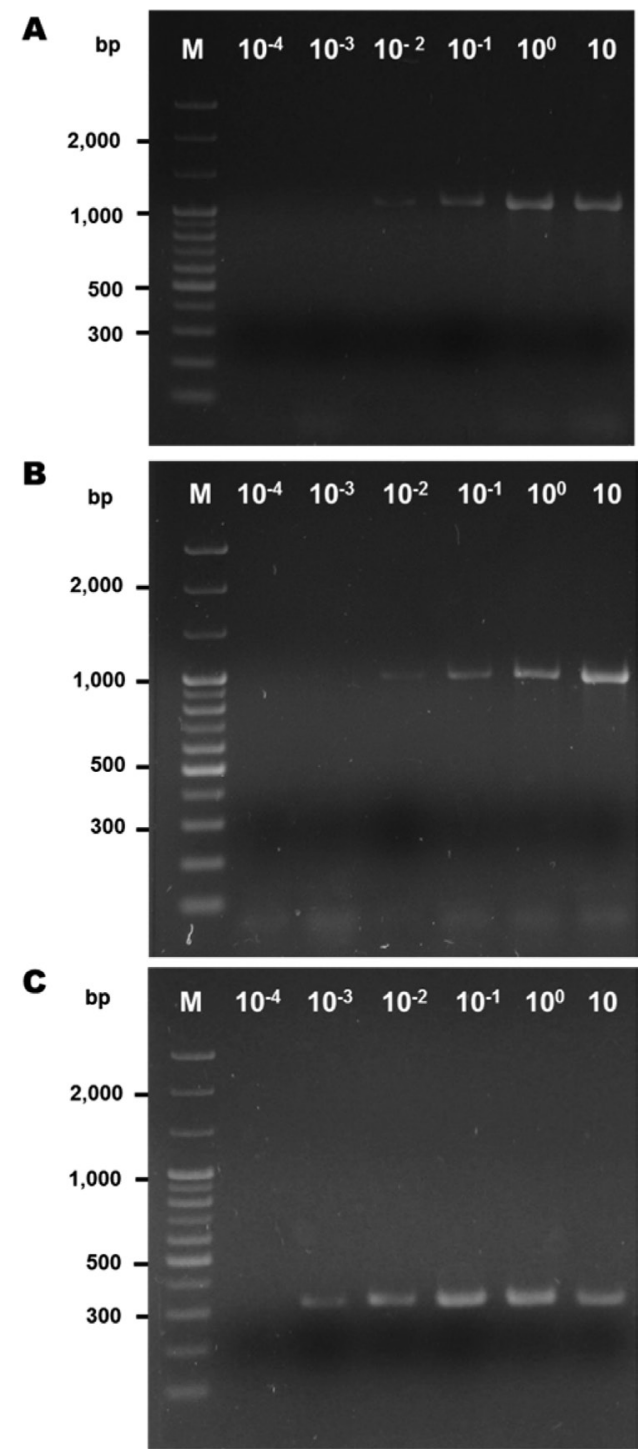

Fig. 3. Primer sensitivity test following genomic DNA 10-fold serial dilution of (A) XAP, (B) XH and (C) XCZ using XPN, XHG and XZRN primer sets, respectively. Lane 1, 100 bp ladder; lane $2-6,10^{-4}, 10^{-3}, 10^{-2}, 10^{-1}, 10^{0}$ and 10 dilutions, respectively.

PCR sensitivity and efficiency. For pathogen quarantine and inspection, primer sets are often required to be not only specific to the templates, but also sensitive to small quantities of the pathogens. Therefore, these primers were found to be highly sensitive and could be used to detect small quantity of bacterial DNA. The detection limit for the primers, XPN and XHG, was $10^{-2} \mathrm{ng} / \mu \mathrm{l}$, whereas XZRN was more sensitive and allowed the detection of $10^{-3} \mathrm{ng} /$ $\mu \mathrm{l}$ of bacterial DNA per reaction (Fig. 3). Furthermore, the PCR efficiency in bacterial and host cell artificial mixture was determined. All three primer sets showed positive results and the specific PCR fragment for each primer set, 
XPN, XHG and XZRN, was amplified from all four hosts and bacterial cell mixture (data not shown). The ability of these primer sets to detect XAP, XH and XCZ pathogen in small quantities suggests that this PCR assay can be used to detect these species in latently infected plants.

Ultimately, the PCR assay described here is a quick, sensitive and more suitable diagnostic tool for the detection of these pathogens. This selective and sensitive method circumvents many problems associated with the current detection techniques, enabling the reliable detection of XAP, $\mathrm{XH}$ and $\mathrm{XCZ}$ at early stages of infection and help monitor diseases.

\section{References}

Adikini, S., Tripathi, L., Beed, F., Tusiime, G., Magembe, E. M. and Kim, D. J. 2011. Development of a specific molecular tool for detecting Xanthomonas campestris pv. musacearum. Plant Pathol. 60:443-452.

Benschop, M., Kamenetsky, R., Le-Nard, M., Okubo, H. and De Hertogh, A. 2010. The global flower bulb industry: Production, utilization, research. Hortic. Rev. 36:1-115.

Bradbury, J. F. 1984. Xanthomonas Dowson 1939. In: Bergey's manual of systematic bacteriology, vol. 1, eds. by N. R. Krieg and J. G. Holt, pp. 199-210. The Williams \& Wilkins Co., Baltimore, Md.

Darrasse, A., Carrere, S., Barbe, V., Boureau, T., Arrieta-Ortiz, M. L. et al. 2013. Genome sequence of Xanthomonas fuscans subsp. fuscans strain 4834-R reveals that flagellar motility is not a general feature of xanthomonads. BMC genomics 14:761.

Janse, J. D. and Miller, H. J. 1983. Yellow disease in Scilla tubergeniana and related bulbs caused by Xanthomonas campestris pv. hyacinthi. Neth. J. Plant Pathol. 89:203-206.

Joubert, J. J. and Truter, S. J. 1972. A variety of Xanthomonas campestris pathogenic to Zantedeschia aethiopica. Neth. J. Plant Pathol. 78:212-217.

Lee, B. M., Park, Y. J., Park, D. S. et al. 2005a. The genome sequence of Xanthomonas oryzae pathovar oryzae KACC10331, the bacterial blight pathogen of rice. Nucleic Acids Res. 33:577-586.

Lee, Y. A., Chen, K. P. and Chang, Y. C. 2005b. First report of bacterial leaf blight of white-flowered calla lily caused by Xanthomonas campestris pv. zantedeschiae in Taiwan. Plant Pathol. 54:239.

Lopez, M. M., Bertolini, E., Olmos, A., Caruso, P., Gorris, M.
T., Llop, P., Penyalver, R. and Cambra, M. 2003. Innovative tools for detection of plant pathogenic viruses and bacteria. Int. Microbiol. 6:233-243.

Lopez, M. M., Llop, P., Olmos, A., Marco-Noales, E., Cambra, M. and Bertolini, E. 2009. Are molecular tools solving the challenges posed by detection of plant pathogenic bacteria and viruses? Curr. Issues Mol. Biol. 11:13-46.

Louws, F. J., Fulbright, D. W., Stephens, C. T. and de Bruijn, F. J. 1994. Specific genomic fingerprints of phytopathogenic Xanthomonas and Pseudomonas pathovars and strains generated with repetitive sequences and PCR. Appl. Environ. Microbiol. 60:2286-2295.

Mavromatis, K., Ivanova, N. N., Chen, I. M. A., Szeto, E., Markowitz, V. M. and Kyrpides, N. C. 2009. Standard operating procedure for the annotations of microbial genomes by the production genomic facility of the DOE JGI. Stand Genomic Sci. 1:63-67.

Ochiai, H., Inoue, Y., Takeya, M., Sasaki, A. and Kaku, H. 2005. Genome sequence of Xanthomonas oryzae pv. oryzae suggests contribution of large numbers of effector genes and insertion sequences to its race diversity. Jpn. Agric. Res. 39:275-287.

Palacio-Bielsa, A., Cambra, M. A. and Lopez, M. M. 2009. PCR detection and identification of plant-pathogenic bacteria: Updated review of protocols (1989-2007). J. Plant. Pathol. 91:249-297.

Rockey, W. 2012. Diversity within Xanthomonas axonopodis poinsettiicola and its role as causal agent of bacterial blight in commercial greenhouse ornamental crops. Master. thesis. University of Florida, Gainesville, USA.

Showmaker, K., Wang, X., Wang, H., Hsu, C. Y., Deng, P., Baird, S. M., Allen, T., Golden, B., Peterson, D., Nichols, R. and Lu, S. E. 2014. Draft genome sequence of Xanthomonas citri pv. malvacearum strain MSCT1 and development of pathovar specific PCR primers. Am. Phytopathol. Soc. 11p. (Abstact)

Smith, I. M., McNamara, D. G., Scott, P. R. and Holderness, M. 1997. Quarantine pests for Europe, 2nd ed. EPPO/CABI International, Wallingford, United Kingdom. 1425pp.

Thieme, F., Koebnik, R., Bekel, T., Berger, C., Boch, J., Büttner, D. et al. 2005. Insights into genome plasticity and pathogenicity of the plant pathogenic bacterium Xanthomonas campestris pv. vesicatoria revealed by the complete genome sequence. $J$. Bacteriol. 187:7254-7266.

Van Doorn, J., Hollinger, T. C. and Oudega, B. 2001. Analysis of the type IV fimbrial-subunit gene fimA of Xanthomonas hyacinthi: Application in PCR-mediated detection of yellow disease in hyacinths. Appl. Environ. Microbiol. 67:598-607. 